\title{
OS CONSUMIDORES CONFIAM NO PRODUTO ORGÂNICO OU ACHAM QUE É ORGANICWASHING?
}

\begin{abstract}
Eloisa Lages Nunes ${ }^{1}$
RESUMO: Buscou-se analisar se a percepção do consumidor para produtos orgânicos afeta sua tomada de decisão de compra e se as estratégias de greenwashing se associam à compra e consumo, sendo aqui chamadas de organicwashing. Como metodologia utilizou-se a pesquisa exploratória, técnica qualitativa, por meio do instrumento de entrevista individual em profundidade, semiestruturada, aplicada a uma amostra intencional não probabilística de 16 consumidores, usando análise de conteúdo para buscar encontrar as percepções, interpretações e motivações dos participantes a respeito do consumo de produtos orgânicos. Foi possível constatar por meio da análise de conteúdo das entrevistas que os consumidores estão mais preocupados com a saúde, entretanto o preço ainda é um fator de decisão para a compra. Evidenciou-se também, de forma clara, que os consumidores associam as práticas de greenwashing aos produtos orgânicos, aqui chamadas de organicwashing.
\end{abstract}

Palavras-chaves: Comportamento do consumidor. Intenção de compra. Produtos orgânicos. Organicwashing. Ceticismo.

ABSTRACT: We sought to analyze whether the consumer's perception of organic products affects their purchase decision making and whether greenwashing strategies are associated with purchase and consumption, being here called organicwashing. As a methodology, exploratory research was used, qualitative technique, through the instrument of individual in-depth interview, semi-structured, applied to an intentional non-probabilistic sample of 16 consumers, using content analysis to seek to find the participants' perceptions, interpretations and motivations about the consumption of organic products. It was possible to verify through the content analysis of the interviews that consumers are more concerned with health, however the price is still a decision factor for the purchase. It was also clear that consumers associate greenwashing practices with organic products, here called organicwashing.

Keywords: Consumer behavior. Buy intention. Organic products. Organicwashing. Skepticism.

\footnotetext{
${ }^{\text {I }}$ Mestre em Administração pela UNESP - FCAV (Faculdade de CIências Agrárias e Veterinárias). Vínculo institucional.CEETEPS - Centro Estadual de Educação Tecnológica Paula Souza. E-mail: eloisalages@gmail.com
} 


\section{INTRODUÇÃO}

É crescente a preocupação com questões ambientais, conforme apontam estudos (Elkington, 2013; Zanirato e Rotondaro, 2016) e também outros relacionados à qualidade de vida, seja associada à saúde, alimentação, ambiente de trabalho e outros (Pratesi et al., 2018; Willett et al., 2019).

À medida que a temática relacionada às questões ambientais ganha força, é imperativo para as organizações repensarem sua razão de ser. Uma das formas é refletir sobre a implementação do triple bottom line, que prevê que os negócios devem se sustentar de forma equilibrada sobre três pilares principais: prosperidade econômica, equidade social e desenvolvimento ambiental (Elkington, 1998; Lin, Hsu, Chang, 2019). Este modelo vem ao encontro dos princípios e objetivos da agricultura orgânica em relação aos benefícios que traz para o meio ambiente e para as pessoas, quando considera o agricultor do ponto de vista social e econômico e o consumidor no sentido de oferecer saúde e, por consequência, qualidade de vida, por meio de alimentos saudáveis (De Wit e Verhoog, 2007; Azevedo, 2012).

Atualmente os consumidores estão mais conscientes de seus direitos e exercem certo poder sobre as questões de responsabilidade socioambiental das organizações, uma vez que buscam adquirir produtos e serviços de empresas que tenham esse olhar para questões ambientais, de qualidade de vida e comércio justo (Zhao et al., 2org; Giri, Mondal e Maiti, 2019).

Já em relação aos padrões de aquisição sob a perspectiva do consumidor é notória sua relação com a saúde e a sustentabilidade, mas cabe ressaltar a importância da segmentação do público para a importância de adquirir e ingerir alimentos mais saudáveis, uma vez que os indivíduos são diferentes $\mathrm{e}$ as variáveis que influenciam seus comportamentos também o são (Van Buul et al., 2019).

Busca-se ainda mapear as percepções a respeito do posicionamento de produtos orgânicos junto aos consumidores e compreender se as características do greenwashing (termo que surgiu na década de 1980 para se referir as organizações que buscavam passar uma imagem de ambientalmente responsáveis, sem necessariamente o serem) podem ser 
percebidas nos produtos orgânicos, sendo aqui chamadas de organicwashing (seguindo a mesma lógica usada pelo greenwashing, mas direcionada aos produtos orgânicos).

Para tanto a revisão de literatura apresentada serviu de arcabouço teórico para municiar as entrevistas.

A escolha do tema ligado aos alimentos orgânicos justifica-se por sua relevância no cenário atual, no qual os sistemas de produção orgânica vêm se destacando, as prateleiras das redes varejistas cedem cada vez mais espaço para os produtos certificados, oferecendo variadas opções para os consumidores que almejam um estilo de vida mais saudável, que além de qualidade de vida buscam se relacionar com marcas e empresas que defendem a preservação do meio ambiente (Braga Junior, Neto e Moraes, 2014).

Embora a agricultura orgânica, como conceito, exista há quase ıoo anos, só atraiu atenção significativa de consumidores, ambientalistas, agricultores e, finalmente, formuladores de políticas em todo o mundo desde meados da década de 1980 (IFOAM, 2019). Segundo a publicação The World of Organic Agriculture (2019) do Instituto de Pesquisa de Agricultura Orgânica (FiBL) e da Federação Internacional de Movimentos da Agricultura Orgânica (IFOAM) a agricultura orgânica mundial movimentou 97 bilhões de dólares em 2017, o que evidencia a relevância do tema.

Correa, Machado e Braga Junior (2018) identificaram que o consumidor está se tornando mais exigente e que as práticas de greenwashing que, por vezes, estão presentes nas embalagens dos produtos chamados verdes ou ecológicos, são percebidas por ele, o que faz com que sua tomada de decisão na escolha de produtos seja afetada.

Se os consumidores são afetados pela percepção que têm das embalagens dos produtos com características de greenwashing, buscou-se identificar se isso se repete em produtos orgânicos - que aqui foram chamadas de organicwashing - bem como pretendeu-se verificar se existe ceticismo por parte do consumidor em relação aos produtos orgânicos.

\section{FUNDAMENTAÇÃO TEÓRICA}

A fundamentação teórica aborda os temas norteadores da pesquisa, sendo: Produto Orgânico, Qualidade de vida e Comportamento do Consumidor. Por meio do 
aprofundamento dos conceitos, buscou-se construir um arcabouço teórico que tratam dos temas em discussão.

\section{I Produto orgânico}

Entende-se como produto orgânico aquele que é cultivado sem a adição de substâncias sintéticas como, por exemplo, fungicidas, pesticidas, fertilizantes, entre outros, chamados geralmente de agrotóxicos, em toda sua cadeia de produção.

Conceituar o alimento orgânico não é algo simples, uma vez que não existe uma única definição universalmente aceita (Qendro, 2015). Contudo, os regulamentos de diversos países não são tão diferentes no que diz respeito ao que se considera produto orgânico, sobretudo em termos de natural e artificial e de insumos permitidos ou não (Seufert, Ramankutty e Mayerhofer, 2017).

\section{I.I Princípios da agricultura orgânica}

Segundo a IFOAM (2019) a agricultura orgânica está embasada nos princípios da saúde, ecologia, equidade, ambiente e saúde. A agricultura orgânica prioriza a qualidade dos alimentos, uma vez que busca a manutenção e preservação do solo, das plantas, dos animais e das pessoas de forma segura e saudável (Migliorini e Wezel, 2017).

Sua base deve constituir relações igualmente justas para todos que fazem parte da cadeia, sejam produtores, processadores, trabalhadores rurais, distribuidores etc. As relações humanas sociais devem priorizar a qualidade de vida e justiça (Andersen et al., 2015; Migliorini e Wezel, 2017). Um dos objetivos da agricultura orgânica é produzir alimentos saudáveis em quantidades suficientes a fim de contribuir com a diminuição da pobreza e fortalecer a segurança alimentar.

\subsubsection{Certificação de produto orgânico}

Com o aumento da preocupação a respeito de questões ambientais, de alimentação saudável, estilo de vida etc. (mencionados por Braga Junior, Neto, Moraes, 2014; Türk e Ercis, 2017), surgiu a necessidade por parte de alguns países em certificar seus processos de 
produção, a fim de garantir que atendessem aos crescentes clamores da sociedade por alimentos mais saudáveis (Pilař et al., 2018).

Tendo como um dos principais atores do cenário da produção orgânica, a Federação Internacional de Movimentos da Agricultura Orgânica (IFOAM) fundada em 1972, estabeleceu o primeiro padrão global em I980 (Fouilleux e Loconto, 2017).

No Brasil os sistemas de produção orgânica no que diz respeito a produção, armazenamento, rotulagem, certificação, comercialização, transporte e fiscalização são regulamentados pela Lei 10.831/2003, seguida por vários Decretos e Instruções Normativas que, além de criar o Sistema Brasileiro de Avaliação da Conformidade Orgânica, trazem novos critérios a todo o sistema de produção orgânica.

A Instrução Normativa no 18 de 20 de junho de 2014 traz orientações em relação à criação do selo oficial do Sistema Brasileiro de Avaliação da Conformidade Orgânica, bem como as condições para sua utilização.

Figura 3 - Selo oficial de certificação orgânica

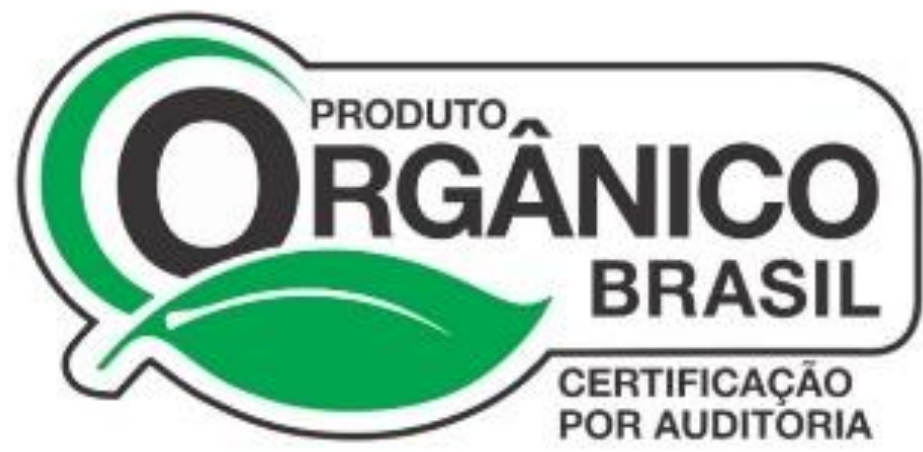

Fonte: Ministério da Agricultura, Pecuária e Abastecimento, 2020

Contar com um único selo brasileiro para certificação dos produtos orgânicos pode ser favorável para a comunicação com os consumidores e construção da credibilidade. A certificação do produto permite construir credibilidade por parte da empresa perante o público, que reconhece a certificação como confiável (Correa, Machado e Braga Junior, 2018). Esta prática também está em conformidade com a lógica adotada pela União 
Europeia que, em 2000, instituiu um selo comum de certificação orgânica, pois existiam vários selos o que ocasionava certa confusão aos consumidores na hora da compra (Zander, Padel e Zanoli, 2015).

E em meio a uma grande variedade de ofertas se dá o processo de escolha pelo consumidor, influenciado por fatores pessoais, de marketing e situacionais (Engel, Blackwell e Miniard, 2000).

No caso das embalagens são abordadas situações de comunicação que ocorrem no cenário de compra, no qual o consumidor pode manipulá-las usando os sentidos da visão e do tato, tendo contato com as cores, texturas, elementos gráficos, além de informações do conteúdo que fazem parte dos fatores situacionais (Engel, Blackwell e Miniard, 20oo; Solomon, 2016).

Sobre as embalagens, Wagner (2015) afirma que o objetivo vai além de acondicionar e proteger o produto, são projetadas para ter uma boa disposição nas prateleiras, que sejam agradáveis ao toque, fáceis de segurar e de abrir e que tragam as informações necessárias ao consumidor. Chrysochou e Festila (2019) afirmam que as embalagens têm um papel fundamental de influenciar os consumidores e para os produtos orgânicos evidenciam o uso de cores, imagens, textos, a apresentação do selo de certificação que atesta que aquele produto é orgânico.

\subsubsection{Ceticismo em relação ao produto orgânico e associação ao greenwashing}

Como visto no decorrer do que foi apresentado acerca de produtos orgânicos e de sua complexidade no que diz respeito a sua caracterização, princípios, qualidades e certificação fica evidente que o consumidor não tem fácil acesso a todas as informações das quais necessita para uma tomada de decisão racional acerca dos produtos que vai colocar em sua mesa, entretanto pesquisas apontam que os consumidores estão mais atentos às suas escolhas alimentares (Türk e Ercis, 2017).

Para tanto existe a certificação que, geralmente, garante a credibilidade necessária para suas escolhas, uma vez que o produto orgânico certificado está posicionado como ecologicamente correto e sustentável (Chrysochou e Festila, 2019). 
Se o produto orgânico está posicionado como ecologicamente correto e sustentável pode ser considerado um produto verde (Chrysochou e Festila, 2019), já que seus processos de produção consideram aspectos inerentes aos impactos ambientais, característica forte da corrente do marketing verde (Patil e Khobarkar, 2019) é de se esperar que os consumidores com certa consciência ecológica passem a adquirir tais produtos (Türk e Ercis, 2017).

É crescente o número de estudos a respeito da preocupação ambiental, tanto por empresas, quanto acadêmicos e um dos principais pontos destes estudos são os consumidores. Também cresce o número de pesquisas a respeito de questões relacionadas ao marketing verde, publicidade ecológica, comportamento ecológico do consumidor, sobre como a publicidade e os rótulos e selos de produtos impactam a escolha por esses produtos (Srivastava, 2017; Bailey, Mishra e Tiamiyu, 2018).

É importante considerar que a confusão e incerteza em alimentos comercializados como saudáveis têm gerado ceticismo por parte dos consumidores e impedindo a compra de alimentos orgânicos (Anisimova, 2016).

A crescente preocupação com questões sociais e regulatórias com o meio ambiente faz com que mais empresas considerem questões ecológicas em suas agendas como estratégia de diferenciação perante o mercado consumidor. As empresas que buscarem se diferenciar por meio de um posicionamento ambiental terão mais competitividade (Srivastava, 2017).

Entender como se comporta o consumidor diante dessas questões ecológicas são fatores importantes para que organizações desenvolvam estratégias para o cumprimento de sua missão (Shinde e Aswale, 2015).

Uma das estratégias utilizadas pelas empresas é o marketing verde que surgiu em meados dos anos 80 como uma forma de produzir e vender produtos que trouxessem benefícios ambientais, bem como buscando minimizar os impactos provocados ao meio ambiente (Braga Junior, Neto e Moraes, 2014; Patil e Khobarkar, 2019). O marketing verde ou ecológico é popular nos países ocidentais, mas há um entendimento limitado por parte de empresas e de consumidores (Khare, 2015).

Esse entendimento limitado leva o consumidor a se tornar cético em relação às mensagens comunicadas pelas empresas e seus produtos no que diz respeito às questões 
ambientais e ao consumo de produtos verdes e orgânicos (Testa, Sarti e Frey, 2019). As mensagens verdes têm como objetivo gerar credibilidade percebida para a marca apresentando os atributos ambientais da empresa e de seus produtos, no entanto, no geral a credibilidade é baixa, levando ao ceticismo (Anisimova, 2016).

Por outro lado, quanto mais conhecimento um consumidor tem a respeito de produtos verdes e questões ambientais, mais capacidade terá na hora de julgar ou comprar um produto verde. Esse aumento de conhecimento pode ser associado ao aumento da atenção às questões ambientais e à intenção de comprar produtos verdes (Silva et al., 2019).

Em relação aos produtos orgânicos uma forma de criar essa consciência é o acesso as informações relacionadas aos produtos ofertados, à medida que os consumidores tenham acesso a essas informações, talvez se sintam compelidos a experimentar o produto (Türk e Ercis, 2017).

No período em que teve origem o marketing verde, década de 1980, também surgiu o greenwashing, e coincidiu com a mesma época em que o discurso sobre sustentabilidade começou a ganhar força globalmente e nas organizações.

Trata-se de desinformações disseminadas por organizações com o objetivo de fazer com o que o público acredite que ela possui uma imagem ambientalmente responsável. O uso de expressões que remetem ao marketing verde como, por exemplo, 'eco', 'sustentável' 'ecológico' podem gerar a confiança ou confundir o consumidor (Braga Junior et al., 2016). Bailey, Mishra e Tiamiyu (2016) identificaram a relação do ceticismo e o impacto das mensagens e esforços de marketing, cujo consumidor altamente cético ou com alto nível de conhecimento tende a ter uma baixa resposta às mensagens.

Correa, Machado e Braga Junior (2018) destacam que muitas organizações se utilizam da prática de greenwashing para estimular o consumidor a criar uma percepção de que o produto é verde, ecológico etc.

Se as mesmas práticas apontadas como greenwashing, que podem levar o consumidor ao engano, são usadas em produtos orgânicos, acredita-se que o consumidor possa se confundir em relação a escolha por estes produtos gerando ceticismo (Copeland e Bhaduri, 2019). 
A expressão "ceticismo verde" é definida como a tendência de o consumidor duvidar dos benefícios ambientais oferecidos pelos produtos verdes (Leonidou e Skarmeas, 2017) e, por extensão de sentido aos produtos orgânicos, uma vez que podem ser considerados verdes e existe desconfiança da qualidade dos produtos orgânicos (Anisimova, 2016).

\subsection{Qualidade de vida}

Muito se fala em qualidade de vida atualmente. E cada vez mais a busca pela qualidade de vida está associada ao ser humano, suas crenças, a cultura a qual pertence e o meio onde vive (Bettine, Gutierrez, Marques, 2019).

Entretanto, não existe uma única definição para o termo, já que se trata de uma área do conhecimento ainda em construção e com uma gama muito grande de dimensões de pesquisa. Existem muitos estudos acerca do conceito de qualidade de vida, que incluem diferentes fatores (Todorovic, Savovic, Dordevic, 2016).

O conceito de qualidade de vida está atrelado à saúde, uma vez que a evolução da

medicina trouxe um aumento na expectativa de vida e, em certa medida, buscou-se mensurar a forma como as pessoas vivem esses anos a mais (Fleck, 2000).

Neste sentido, a escolha por produtos orgânicos se torna um importante diferencial em vista do crescente interesse por parte do público consumidor em levar uma vida mais saudável (Anisimova, 2016; Türk e Ercis, 2017).

\subsection{Comportamento do consumidor}

É crescente o número de consumidores que buscam por empresas que estejam atentas ao impacto ambiental e que, de alguma forma, busquem práticas ambientalmente corretas, seja em sua produção ou em seus processos, ainda que tais diferenciais não sejam totalmente exigidos por lei (Colares e Mattar, 2016; Gomes e Junior, 2016).

O comportamento do consumidor é influenciado por uma série de fatores ambientais que fazem parte da cultura de uma sociedade, dos grupos de referência com os quais convivem, influências de mercado, como, propagandas, acesso ao crédito e influências situacionais que dizem respeito à aspectos relacionados ao ambiente, a 
disposição de compra etc., aspectos relevantes para a tomada de decisão de compra (Correia et al., 2017).

Cabe ressaltar que em estudos de comportamento do consumidor existe uma lacuna entre a intenção declarada e o comportamento real, uma vez que os indivíduos tendem a declarar atitudes aceitáveis em casos de comportamentos ecológicos (Testa, Sarti e Frey, 2019).

\section{PROCEDIMENTOS METODOLÓGICOS}

A fim de verificar a ocorrência dos objetivos propostos utilizou-se a pesquisa exploratória, usando a técnica qualitativa, por meio do instrumento de entrevista individual em profundidade, semiestruturada, aplicada a uma amostra intencional não probabilística, usando análise de conteúdo para buscar encontrar as percepções, interpretações e motivações dos participantes a respeito do consumo de produtos orgânicos.

As técnicas qualitativas são usadas tanto para a coleta de dados, quanto para a análise dos resultados. Para a coleta será usado como instrumento a entrevista semiestruturada em profundidade e para apresentação de resultados e discussões a técnica de análise de conteúdo (Cooper e Schindler, 2016; Bardin, 1977).

Para apresentar os resultados da pesquisa realizada, a análise de conteúdo se faz necessária, por se tratar de um "conjunto de técnicas de análise de comunicações" (Bardin, 1977, p. 31). A análise de conteúdo objetiva uma amplitude no sentido de buscar na leitura crítica e minuciosa dos dados as percepções e significações explícitas ou implícitas, ocultas (Mozzato e Grzybovski, 20II).

Dessa forma a pesquisa qualitativa produziu elementos suficientes para a identificação e análise dos fenômenos envolvidos no comportamento do consumidor de produtos orgânicos.

Foram selecionadas i6 pessoas do sexo masculino e feminino a fim de serem entrevistados para a presente pesquisa. 
Quanto às variáveis desta pesquisa para caracterização do perfil dos respondentes, foi constituída pelos itens: sexo, faixa etária, estado civil, grau de instrução, renda familiar (metodologia de estratificação do IBGE) e país de residência.

\section{RESULTADOS E DISCUSSÕES}

Neste capítulo são apresentados os resultados e as discussões a respeito das entrevistas feitas com 16 consumidores de produtos orgânicos, realizadas entre os meses de junho e julho de 2020 .

Para assegurar o anonimato dos respondentes, mas tendo como objetivo evidenciar algumas falas relevantes para corroborar a inferência e interpretação da pesquisa, os participantes foram identificados a partir de uma codificação que vai de Rı a Rı6.

No que diz respeito à interpretação dos dados é importante que se faça a relação com a fundamentação teórica, uma vez que ela dá o embasamento para que a interpretação faça sentido (Câmara, 2013).

As categorias foram criadas previamente com base nas perguntas norteadoras do

roteiro da entrevista semiestruturada aplicada aos respondentes, conforme apresentadas no Quadro I.

Quadro I - Categorias para análise de conteúdo

\begin{tabular}{|l|l|}
\hline Categoria & Justificativa \\
\hline Consumo de produtos orgânicos & $\begin{array}{l}\text { Verificar quais são os produtos orgânicos } \\
\text { consumidos pelos respondentes e identificar } \\
\text { se o consumo de orgânicos refere-se a } \\
\text { alimentos }\end{array}$ \\
\hline $\begin{array}{l}\text { Motivos para o consumo de } \\
\text { produtos orgânicos }\end{array}$ & $\begin{array}{l}\text { Identificar a motivação dos respondentes em } \\
\text { consumir produtos orgânicos }\end{array}$ \\
\hline $\begin{array}{l}\text { Percepção quanto ao preço de } \\
\text { produtos orgânicos }\end{array}$ & $\begin{array}{l}\text { Identificar nos respondentes sua percepção } \\
\text { sobre o preço dos produtos orgânicos }\end{array}$ \\
\hline $\begin{array}{l}\text { Motivos que levam as pessoas a } \\
\text { consumirem orgânicos }\end{array}$ & $\begin{array}{l}\text { Identificar qual é a percepção dos } \\
\text { respondentes em relação ao consumo de } \\
\text { produtos orgânicos por outras pessoas }\end{array}$ \\
\hline $\begin{array}{l}\text { Motivos que levam as pessoas a } \\
\text { NÃO consumirem orgânicos }\end{array}$ & $\begin{array}{l}\text { Identificar qual é a percepção dos } \\
\text { respondentes em relação aos motivos que } \\
\text { podem ter as pessoas que não consomem } \\
\text { orgânicos a }\end{array}$ \\
\hline Ceticismo em relação aos & \begin{tabular}{l} 
Identificar se o respondente já teve alguma \\
\hline
\end{tabular}
\end{tabular}




\begin{tabular}{|l|l|}
\hline produtos orgânicos & $\begin{array}{l}\text { desconfiança em relação ao produto orgânico } \\
\text { e se teve, por qual(ais) motivo(s) }\end{array}$ \\
\hline $\begin{array}{l}\text { O ceticismo pode estar presente } \\
\text { na percepção de outras pessoas }\end{array}$ & $\begin{array}{l}\text { Identificar entre os respondentes se eles têm a } \\
\text { percepção de que outras pessoas possam } \\
\text { desconfiar de produtos orgânicos e por } \\
\text { qual(ais) motivo(s) }\end{array}$ \\
\hline $\begin{array}{l}\text { Diferenciação de produtos } \\
\text { orgânicos }\end{array}$ & $\begin{array}{l}\text { Identificar como o respondente distingue um } \\
\text { produto orgânico de um não orgânico (ou } \\
\text { convencional) }\end{array}$ \\
\hline $\begin{array}{l}\text { Crença sobre o que é produto } \\
\text { orgânico }\end{array}$ & $\begin{array}{l}\text { Identificar se as pessoas, inclusive produtores } \\
\text { sabem o que é produto orgânico na percepção } \\
\text { do respondente }\end{array}$ \\
\hline $\begin{array}{l}\text { Ceticismo sobre os fatores sociais } \\
\text { e comportamentais }\end{array}$ & $\begin{array}{l}\text { Identificar, na percepção do respondente o } \\
\text { que ele acha sobre as pessoas desconfiarem de } \\
\text { produtos orgânicos, mesmo os consumindo }\end{array}$ \\
\hline $\begin{array}{l}\text { Ceticismo sobre os fatores de } \\
\text { influência de marketing e } \\
\text { situacionais }\end{array}$ & $\begin{array}{l}\text { Identificar, na percepção do respondente o } \\
\text { que os produtores usam como artifício para } \\
\text { induzir o consumidor a acreditar que seus } \\
\text { produtos são orgânicos }\end{array}$ \\
\hline Atitudes ambientais & $\begin{array}{l}\text { Identificar a percepção dos respondentes a } \\
\text { respeito da proteção à natureza por parte dos } \\
\text { produtores }\end{array}$ \\
\hline
\end{tabular}

Fonte: Elaborado pela autora da pesquisa com base no roteiro de entrevista, 2020

A partir da análise do conteúdo das entrevistas foi possível identificar que, para as categorias 'Consumo de produtos orgânicos' e 'Motivos para o consumo de produtos orgânicos' (que correspondem ao primeiro objetivo específico desta pesquisa e se referem a identificação das características reconhecidas pelo consumidor para produtos orgânicos) nove entre i6 respondentes identificam o produto orgânico como sendo aquele livre de hormônios, agrotóxicos, com menos químicos, menos conservantes, menos pesticidas e que agridem menos o meio ambiente.

Lembrando que uma das premissas da produção de alimentos orgânicos é a não utilização de agrotóxicos e fertilizantes sintéticos (Ueasangkonsate e Santitterakul, 2016) e isso é um indício de que os pesquisados demonstram ter conhecimento sobre o assunto.

Perguntados sobre quais são os motivos para consumirem produtos orgânicos, a maioria dos respondentes alegaram saúde, o que também está associado ao quarto objetivo que busca verificar a influência da qualidade de vida em suas escolhas, e grande parte dos 
respondentes também alegou que consomem produtos orgânicos por serem livres de agrotóxicos.

Sendo o preço um dos atributos que interferem na tomada de decisão de compra de produtos orgânicos Testa, Sarti e Frey (2019), todos os respondentes concordam que os orgânicos são mais caros que os convencionais.

Perguntou-se o quê na opinião dos respondentes justificaria essa diferença de preço entre alimentos orgânicos e não-orgânicos e a maioria afirmou explicitamente que o fato de não levar agrotóxicos requer mais cuidados para lidar com as pragas, além de a produção ter de ser em escala não massificada.

Foram feitas perguntas para captar a percepção dos respondentes a respeito dos motivos que levam ou não as demais pessoas a consumirem produtos orgânicos. $\mathrm{Na}$ percepção dos respondentes um dos principais motivos que levam as outras pessoas a consumirem produtos orgânicos é a preocupação com a saúde.

Já para aqueles que não consomem produtos orgânicos, os motivos apresentados foram, de forma unânime, o alto preço.

Cabe destacar que já começam a aparecer indícios que refletem aos questionamentos feitos a respeito do que se queria verificar com a presente pesquisa, ou seja, se acontece organicwashing, já que um respondente afirmou que, talvez, as pessoas não se sintam confortáveis em consumir orgânicos porque "desconfiam e acham que o orgânico é um grande selo verde para vender mais caro" (RI6).

O segundo objetivo específico da pesquisa busca identificar se os entrevistados percebem características nos produtos orgânicos que podem ser associadas ao greenwashing, aqui chamadas de organicwashing. Para tanto as categorias que buscaram verificar essa ocorrência, também foram geradas com base no roteiro de entrevistas.

As categorias 'ceticismo em relação ao produto orgânico', 'ceticismo em relação ao produto orgânico pelas pessoas na percepção dos respondentes' e 'distinção dos produtos orgânicos' trouxeram revelações importantes, relacionando as práticas de greenwashing aos orgânicos.

Foi possível identificar que a maioria dos respondentes desconfia dos produtos orgânicos, entretanto também evidenciou-se que os respondentes que moram em outros 
países não desconfiam na mesma proporção, afirmando que existe mais confiança até porque os temas relacionados ao consumo de produtos orgânicos, preservação do meio ambiente e outros relacionados, como o veganismo, por exemplo, são muito debatidos, principalmente entre os mais jovens.

A seguir algumas respostas que evidenciam o ceticismo do consumidor de produtos orgânicos.

Eu tento confiar... (RI)

Já desconfiei, geralmente no supermercado comum... $\left(\mathrm{R}_{3}\right)$

Para ser sincero eu desconfio o tempo todo... (RII)

Alguns aspectos observados pelos respondentes que geram desconfiança em relação a oferta de produtos orgânicos são intrínsecos aos fatores de influência situacionais que dizem respeito ao ambiente de compra, layout do ponto de venda etc. (Solomon, 2016; Correia et al., 2017). Esses aspectos atendem ao quinto objetivo específico da pesquisa que busca aferir o nível de influência desses elementos na tomada de decisão.

Nas declarações a seguir é possível identificar alguns aspectos relacionados aos fatores situacionais e que demonstram o ceticismo dos consumidores.

... dependendo do local onde são vendidos eu desconfio... ( $\left.\mathrm{R}_{2}\right)$

... o Pão de Açúcar é um mercado confiável... (R8)

... em supermercado em olho muito o rótulo... (RI6)

A palavra greenwashing surgiu durante a entrevista por parte de duas respondentes associando-a aos produtos orgânicos o que indica que consumidores com conhecimento sobre a prática acreditam que pode acontecer com os produtos que se dizem orgânicos. A seguir os trechos das entrevistas que indicam a associação.

... só porque tem escrito que é orgânico, já acontece uns greenwashing aí, de colocar um rótulo de orgânico e poder cobrar mais caro... ( $\left.\mathrm{R}_{2}\right)$

... minha área é moda, a gente tem muito o greenwashing [...], óbvio que eu desconfio, porque eu tenho conhecimento de causa... (R6)

Se as práticas de greenwashing, que podem levar o consumidor ao engano, são usadas em produtos orgânicos acredita-se que o consumidor possa se confundir em relação a escolha por estes produtos gerando ceticismo (Copeland e Bhaduri, 2019). 
A expressão “ceticismo verde" é definida como a tendência de o consumidor duvidar dos benefícios ambientais oferecidos pelos produtos verdes (Leonidou e Skarmeas, 2017) e, por extensão de sentido aos produtos orgânicos, uma vez que podem ser considerados verdes gerando desconfiança da qualidade destes produtos (Anisimova, 2016). A seguir a demonstração de trechos das entrevistas que indicam o ceticismo verde.

Se a banana é tão linda e sem as manchinhas [...], mas a gente sabe que o orgânico mesmo não tem esse aspecto comercial, de aparência, todos iguais, mesmo tamanho. Na produção orgânica a natureza age por si... $\left(\mathrm{R}_{2}\right)$

... dizem que [...] é orgânico, mas ele não é roo\% orgânico... $\left(\mathrm{R}_{3}\right)$

... até quem tem um certo conhecimento é enganado, a aparência do produto, o orgânico não é tão bonito... ( $\left.\mathrm{R}_{4}\right)$

Anisimova (2016), enfatiza que o uso de mensagens verdes apresentando os atributos e benefícios do produto têm como objetivo gerar credibilidade percebida para a marca, no entanto, no geral a credibilidade é baixa, levando ao ceticismo. De forma semelhante o uso do marketing verde, popular nos países ocidentais, ainda provoca um entendimento limitado por parte de empresas e consumidores (Khare, 2015). É possível verificar nas entrevistas que ainda existem, por parte dos consumidores, dúvidas em relação às características, atributos e benefícios do produto orgânico.

... claro que, às vezes, a embalagem, a marca podem me dar uma sensação de conforto, mas nem sempre sinto essa segurança... (RII)

... não sei se as pessoas pensam muito nesses detalhes na hora de comprar assim, verduras e sei lá, não sei se as pessoas começam a prestar mais atenção quando é mais industrializado... ( $\left.\mathrm{R}_{14}\right)$

... diz orgânico, mas tu vai lá e tem conservante... (RI6)

Türk e Ercis (2017) consideram que uma forma de criar consciência em relação aos produtos orgânicos é o acesso às informações, pois argumentam que à medida que os consumidores tenham acesso a elas, talvez se sintam compelidos a experimentar o produto.

... se as pessoas buscam mais informações talvez tenham mais condições de diferenciar os produtos orgânicos... ( $\left.\mathrm{R}_{4}\right)$

... se buscarem informações isso muda... (R8)

... acho que o grau de instrução e idade interferem, informação... (Rio) 
Silva et al. (2019) destacam que a cultura influencia as relações e interações do mercado o que inclui a comunicação entre empresa e consumidor e vários estudos apontam que em países emergentes ou em desenvolvimento a confiança dessas relações tende a ser mais fraca e que em países desenvolvidos, os consumidores têm mais conhecimento e poder de barganha e que as empresas estão mais abertas as discussões.

A seguir trechos das entrevistas que confirmam as afirmações de Silva et al. (2019). ... quando morei na Alemanha, o povo lá é mais consciente, inclusive fazendo boicote... $\left(\mathrm{R}_{2}\right)$

... no ano que vivi na França eu confiava... (Rı3)

...aqui na Europa não há tanta desconfiança, [...], mas no Brasil eu via muito sim... (RI6)

Identificou-se nas entrevistas uma série de afirmações em relação ao uso do selo de certificação de produtos orgânicos, seja no Brasil ou em outros continentes. A certificação do produto permite construir credibilidade por parte da empresa perante o público, que reconhece a certificação como confiável (Correa, Machado e Braga Junior, 2018). Observou-se que o uso do selo por parte dos produtores gera diferentes percepções por parte dos respondentes e que podem estar relacionadas às diferentes culturas nas quais estão inseridos.

De fato, como coloca Brécard (2017), o aumento do número de rótulos relacionados à produtos verdes, desde a década de 90 , pode ter contribuído para que o consumidor tivesse uma percepção equivocada, trazendo ceticismo.

Abaixo trechos das entrevistas que ilustram as diferentes percepções em relação ao selo de certificação de produto orgânico.

... tudo bem, tem o selo, mas quem garante $\left(R_{4}\right)$

... eu acho que tem esse chavão de não acreditar ainda que tenha o selo de qualidade... (RIs)

... acham que o orgânico é um grande selo verde para vender mais caro... (RI6)

Por outro lado, os trechos a seguir demonstram como os respondentes diferenciam os produtos orgânicos de não orgânicos, sendo basicamente citadas a questão da aparência e a confiança na procedência. O selo e a embalagem foram pouco citados. 
... aparência, a gente espera que o orgânico não seja tão uniformizado, sem manchas... $\left(\mathrm{R}_{2}\right)$

... se for de um agricultor familiar, gera mais confiança $\left(\mathrm{R}_{3}\right)$

... tentei entender a cadeia de produção e descobrir de onde é... (Rı6)

Cabe destacar que aquilo que define o comportamento de compra de produtos orgânicos permanece incerto, uma vez que os determinantes estão baseados nos objetivos autodeclarados pelos consumidores e que há discrepância entre intenção e comportamento. Outro ponto a ser considerado são os fatores de influência sociais, os grupos de referência e variáveis demográficas (Testa, Sarti e Frey, 2019).

Esses fatores de influência fazem parte do processo de tomada de decisão de compra do consumidor que é composto por cinco estágios, sendo dois deles a busca de informações e a avaliação de alternativas (Solomon, 2016). Estes estágios são importantes na medida em que as empresas usam de estratégias de comunicação e marketing verde em sua oferta de produtos a fim de captar a atenção dos consumidores.

Sendo a embalagem um dos elementos do composto de marketing que exerce influência sobre as escolhas dos consumidores, que trata da promoção e comunicação dos atributos dos produtos, também se vale do uso de formatos, cores, tamanhos entre outras características (Solomon, 2016).

Alguns exemplos de estudos que investigam o uso de elementos que remetem à natureza nas embalagens para referenciar produtos orgânicos seriam Matthes, Wonneberger e Schmuck (2014), Papadas, Avlonitis e Carrigan (2017), Chrysochou e Festila (2019).

Vejamos quais são os trechos das entrevistas que se relacionam ao objetivo no que diz respeito aos fatores de influência de marketing e situacionais.

Percebe-se que os respondentes mencionam que as estratégias de marketing podem influenciar sua decisão de compra pelo orgânico ao afirmarem que a comunicação visual das embalagens, a cor verde, o selo e as próprias "estórias" contadas nas propagandas acabam funcionando. No entanto, é possível verificar que novamente aparece a categoria que trata do ceticismo dos consumidores no teor do que está escrito nas embalagens, ou 
seja, há desconfiança em relação ao que as empresas querem vender como verdade e, portanto, alguns trechos denotam indícios de que o consumidor percebe algum tipo de organicwashing nos produtos que analisa.

... embalagens vivas, com transparência [...] usam a cor verde que remete a natureza, imagem de folhagens, embalagens que lembram produtos recicláveis... $(\mathrm{R} I)$

... marketing, o próprio selo, a propaganda, colocar atributos de qualidade... ( $\left.\mathrm{R}_{3}\right)$

... marketing, vendem uma coisa que não é, maquiagem de informação, [...] colocam uma palavra [...] no rótulo, na propaganda, na embalagem... (R8)

Foi evidenciado que ceticismo se estende aos produtos verdes e orgânicos na medida em que consumidor questiona se as informações acerca do produto são verdadeiras com base na percepção de ações de marketing (Romani, Grappi e Bagozzi, 2014).

Reforçando esta crítica, Solomon (2016) apresenta uma pesquisa realizada com consumidores norte-americanos, a qual aponta que o percentual que pagava mais por produtos verdes caiu entre os anos de 2008 e 2012. Essa queda se deve ao ceticismo gerado pela prática de greenwashing, de acordo com um relatório que aponta que mais de $95 \%$ das empresas de consumo que se promovem como 'ecológicas' fazem alegações enganosas ou imprecisas.

Uma vez que esta pesquisa introduz o tema com a narrativa da preocupação com questões ambientais, tanto por parte de empresas, quanto por parte da sociedade, foi perguntado aos entrevistados se eles achavam que os produtores deveriam proteger a natureza, bem como ter atitudes e processos ambientalmente corretos. A grande maioria dos respondentes afirmou que sim.

De modo geral, todos os respondentes salientaram a importância de cuidar da saúde dos indivíduos, da proteção aos recursos da natureza, do não uso de agrotóxicos, bem como da importância de ter cuidado com os processos envolvidos na cadeia de produção orgânica e que essa deveria ser uma preocupação de todas as empresas e de todos os indivíduos.

\section{CONSIDERAÇÕES FINAIS}

Como objetivo central desta pesquisa buscou-se identificar se existe relação entre as características percebidas do greenwashing na escolha e na compra de produtos orgânicos. 
Mais especificamente sobre suas crenças a respeito das características dos produtos que se dizem orgânicos e relacionar à prática de greenswahing surgida na década de 1980. Buscou-se identificar se a mesma prática ocorria com os produtos orgânicos e que neste trabalho foi chamada de organicwashing.

Partindo da revisão de literatura, aprofundou-se o entendimento do tema para posteriormente realizar a pesquisa de campo, tendo a fundamentação pavimentado a elaboração do instrumento de coleta de dados a partir dos principais assuntos, quais sejam, produtos orgânicos, qualidade de vida e comportamento do consumidor.

Com base na fundamentação teórica, a pesquisa realizada trouxe importantes contribuições para as organizações agroindustriais do ponto de vista de como o consumidor percebe os produtos orgânicos e as estratégias usadas por essas empresas para ofertar seus produtos.

A análise de resultados permitiu perceber que a maioria dos entrevistados reconhece como principal característica do produto orgânico a não utilização de agrotóxicos, mas consideram que, talvez, não tenham um entendimento mais aprofundado para identificar outras etapas do processo de caracterização dos sistemas de produção orgânicos.

Para a maioria dos entrevistados o não uso dos agrotóxicos está estreitamente relacionado com a qualidade de vida, uma vez que os produtos são mais saudáveis, e, portanto, oferecem benefícios a saúde de quem os consome.

Todos os entrevistados têm nível superior de educação, mesmo grande parte deles afirmando que pesquisam e buscam informações, salientaram que os produtores precisam mostrar mais seus processos de produção, a fim de que o consumidor encontre as informações de que necessita para fazer as melhores escolhas, além de criar um relacionamento de transparência.

A análise dos fatores de influência pessoais, de marketing e situacionais evidenciou que o consumidor reconhece que a prática de greenwashing também é utilizada no segmento de produtos orgânicos, gerando ceticismo. É mais um aspecto a ser considerado pelos produtores para serem transparentes em seus processos, podendo criar uma vantagem competitiva. 
O uso do selo de certificação de produtos orgânicos não gera, por parte do consumidor, credibilidade, sem que haja pela maioria questionamentos a respeito de sua veracidade.

\section{REFERÊNCIAS BIBLIOGRÁFICAS}

ANDERSEN, Martin Marchman et al.. Feasibility of new breeding techniques for organic farming. Trends in Plant science, v. 20, n. 7, p. 426-434, 2015.

ANISIMOVA, Tatiana. Integrating multiple factors affecting consumer behavior toward organic foods: The role of healthism, hedonism, and trust in consumer purchase intentions of organic foods. Journal of Food Products Marketing, v. 22, n. 7, p. 809-823, 2016.

AZEVEDO, Elaine de. Alimentos orgânicos: ampliando os conceitos de saúde humana, ambiental e social. São Paulo: Editora Senac São Paulo, 2012.

BAILEY, Ainsworth A.; MISHRA, Aditya S.; TIAMIYU, Mojisola F. Application of GREEN scale to understanding US consumer response to green marketing 341 communications. Psychology \& Marketing, v. 35, n. II, p. 863-875, 2018.

BARDIN, Laurence. Análise de conteúdo. Lisboa: Ediçoes 70, 1977.

BETTINE, Marco. GUTIERREZ, Gustavo. MARQUES, Renato. Qualidade de vida: definição, conceitos e interfaces com outras áreas de pesquisa. São Paulo: Edições EACH, 2019 .

BRAGA JUNIOR, Sergio Silva et al.. Verdadeiro ou falso: a percepção do consumidor para o consumo verde no varejo. Revista Brasileira de Marketing, v. I5, n. 3, p. 390-400, 2016.

BRAGA JUNIOR, Sergio Silva. NETO, Alipio Ramos Veiga. MORAES, Nelson Russo. Atributos de estilo de vida do consumidor relacionados ao consumo de produtos orgânicos no varejo especializado. In: REMark - Revista Brasileira de Marketing, São Paulo, v. I3, n. 5, jul./set. 2014 .

BRÉCARD, Dorothée. Consumer misperception of eco-labels, green market structure and welfare. Journal of Regulatory Economics, v. 51, n. 3, p. 340-364, 2017. 
CÂMARA, Rosana Hoffman. Análise de conteúdo: da teoria à prática em pesquisas sociais aplicadas às organizações. Gerais: Revista Interinstitucional de Psicologia, v. 6, n. 2, p. 179-191, 2013.

CHRYSOCHOU, Polymeros; FESTILA, Alexandra. A content analysis of organic product package designs. Journal of Consumer Marketing, 2019.

COLARES, Ana Carolina Vasconcelos; MATTAR, Patricia. Produtos verdes: Análise das características potencialmente influenciadoras dos consumidores sustentáveis. REUNIR Revista De Administração Contabilidade E Sustentabilidade, v. 6, n. I, p. 56-73, 2016.

COPELAND, Lauren; BHADURI, Gargi. Consumer relationship with proenvironmental apparel brands: effect of knowledge, skepticism and brand familiarity. Journal of Product \& Brand Management, 2019.

CORREA, Caroline Miranda; MACHADO, João Guilherme de Camargo Ferraz; BRAGA JUNIOR, Sergio Silva. A Relaçao do Greenwashing com a Reputação da Marca e a Desconfiança do Consumidor. Revista Brasileira de Marketing, v. 17, n. 4, p. 590-602, 2018.

CORREIA, José Jonas Alves et al.. A psicologia econômica na análise do comportamento do consumidor. Revista Brasileira de Marketing, v. I6, n. 2, p. 218-229, 2017.

COOPER, Donald R. SHINDLER, Pamela S. Métodos de pesquisa em administração. I2 ed. Porto Alegre: AMGH, 2016.

DE WIT, Jon; VERHOOG, Hans. Organic values and the conventionalization of organic agriculture. NJAS-wageningen journal of life sciences, v. 54, n. 4, p. 449-462, 2007.

ENGEL, James F. BLACKWELL, Roger D. MINIARD, Paul W. Comportamento do consumidor. $8^{\mathrm{a}}$ ed. Rio de Janeiro: LTC Editora, 2000.

ELKINGTON, John. Enter the triple bottom line. In: The triple bottom line. Routledge, 2013. P. 23-38.

ELKINGTON, John. Partnerships from cannibals with forks: The triple bottom line of 21: ${ }^{\text {st }}$-century business. Environmental quality management, v. 8, n. I, p. 37-51, 1998.

FLECK, Marcelo Pio de Almeida. O instrumento de avaliação de qualidade de vida da Organização Mundial da Saúde (WHOQOL-10o): características e perspectivas. Ciênc. Saúde coletiva, Rio de Janeiro , v. 5, n. I, p. 33-38, 2000 Disponível em: 
http://www.scielo.br/scielo.php?script=sci_arttext\&pid=SI4I3-

81232000000100004\&lng=en\&nrm=iso. Acesso em: jul. 2019.

FOUILLEUX, Eve; LOCONTO, Allison. Voluntary standards, certification, and accreditation in the global organic agriculture field: a tripartite model of technopolitics. Agriculture and Human Values, v. 34, n. I, p. I-I4, 2017.

GIRI, Raghu Nandan; MONDAL, Shyamal Kumar; MAITI, Manoranjan. Government intervention on a competing supply chain with two green manufacturers and a retailer. Computers \& Industrial Engineering, v. I28, p. I04-I2I, 2019.

GOMES, Nivaldo Simões; JÚNIOR, Eloy Fassi Casagrande. O conhecimento e o ponto de vista de consumidores a respeito da rotulagem ambiental de produtos.Sustainability in Debate, v. 7, n. 3, 2016.

GOVERNO FEDERAL. Lei № http://www.planalto.gov.br/ccivil_03/leis/2003/lio.83r.htm. Acesso em: 26 abril 2020. IFOAM. The world of organic agriculture: Statistics and emerging trends 2019. Geneva: FiBL \& IFOAM Organics International, 2019.

KHARE, Arpita. Influence of green self-identity, past environmental behaviour and income on Indian consumers' environmentally friendly behaviour. Journal of Global Scholars of Marketing Science, v. 25, n. 4, p. 379-395, 2015.

LEONIDOU, Constantinos N.; SKARMEAS, Dionysis. Gray shades of green: Causes and consequences of green skepticism. Journal of Business Ethics, v. I44, n. 2, p. 401-415, 2017 .

LIN, Tyrone T.; HSU, Shu-Yen; CHANG, Chiao-Chen. Evaluation of decision-making for the optimal value of sustainable enterprise development under global roo index thinking. Sustainability, v. II, n. 4, p. II06, 2019.

MATTHES, Jörg; WONNEBERGER, Anke; SCHMUCK, Desirée. Consumers' green involvement and the persuasive effects of emotional versus functional ads. Journal of Business Research, v. 67, n. 9, p. 1885-1893, 2014.

MIGLIORINI, Paola; WEZEL, Alexander. Converging and diverging principles and practices of organic agriculture regulations and agroecology. A review. Agronomy for sustainable development, v. 37, n. 6, p. 63, 2017. 
MOZZATO, Anelise Rebelato; GRZYBOVSKI, Denize. Análise de conteúdo como técnica de análise de dados qualitativos no campo da administração: potencial e desafios. Revista de Administração Contemporânea, v. 15, n. 4, p. 731-747, 201 I.

PAPADAS, Karolos-Konstantinos; AVLONITIS, George J.; CARRIGAN, Marylyn. Green marketing orientation: Conceptualization, scale development and validation. Journal of Business Research, v. 8o, p. 236-246, 2017.

PATIL, Aishwarya; KHOBARKAR, Vanita. Green Marketing. Journal of the Gujarat Research Society, v. 21, n. 16, p. 657-662, 2019.

PILA $\check{R}$, Ladislav et al.. Customer experience with organic food: global view. Emirates Journal of Food and Agriculture, p. 918-926, 2018.

PRATESI, Claudia B. et al.. Quality of life of celiac patients in Brazil: Questionnaire translation, cultural adaptation and validation. Nutrients, v. Io, n. 9, p. 1167, 2018.

QENDRO, Athina-Evera. Albanian and UK consumers' perceptions of farmers' markets and supermarkets as outlets for organic food: An exploratory study. Sustainability, v. 7, n. 6, p. 6626-6651, 2015 .

ROMANI, Simona; GRAPPI, Silvia; BAGOZZI, Richard P. Corporate socially responsible initiatives and their effects on consumption of green products. Journal of Business Ethics, v. 135, n. 2, p. 253-264, 2016.

SEUFERT, Verena; RAMANKUTTY, Navin; MAYERHOFER, Tabea. What is this thing called organic?-How organic farming is codified in regulations. Food Policy, v. 68, p. 10-20, 2017 .

SHINDE, Asha; ASWALE, Sanjay. A Study of Perception Of Consumption of Green Product In Pune City. ASM's International E-Journal on Ongoing Research in Management and IT. INCON - X 2015.

SILVA, Minelle E. et al.. Exploring nuances of green skepticism in different economies. Marketing Intelligence \& Planning, 2019.

SOLOMON, Michael R. O comportamento do consumidor: comprando, possuindo e sendo. $\mathrm{II}^{\mathrm{a}}$ ed. Porto Alegre: Bookman, 2016.

SRIVASTAVA, Vibhava. Exploring Skepticism Toward Green Advertising: An ISM Approach. International Journal of Business Analytics and Intelligence, v. 5, n. I, p. 3, 2017. 
TESTA, Francesco; SARTI, Silvia; FREY, Marco. Are green consumers really green? Exploring the factors behind the actual consumption of organic food products. Business Strategy and the Environment, v. 28, n. 2, p. 327-338, 2019.

TÜRK, Bahar; ERCIŞ, Aysel. 4A marketing mix impacts on organic food purchase intention. Serbian Journal of Management, v. 12, n. 2, p. 189-199, 2017.

UEASANGKONSATE, Pittawat; SANTITEERAKUL, Salinee. A study of consumers' attitudes and intention to buy organic foods for sustainability. Procedia Environmental Sciences, v. 34, p. 423-430, 2016.

VAN BUUL, Vincent J. et al.. Use of nutritional information: analysing clusters of consumers who intend to eat healthily. Journal of nutritional science, v. 8, 2019.

WAGNER, Karin. Reading packages: Social semiotics on the shelf. Visual communication, v. I4, n. 2, p. 193-220, 2015.

ZANDER, Katrin; PADEL, Susanne; ZANOLI, Raffaele. EU organic logo and its perception by consumers. British Food Journal, 2015.

ZANIRATO, Silvia Helena; ROTONDARO, Tatiana. Consumo, um dos dilemas da sustentabilidade. Estudos Avançados, v. 30, n. 88, p. 77-92, 2016.

ZHAO, Daozhi et al.. Channel selection and pricing decisions considering three charging modes of production capacity sharing platform: A sustainable operations perspective. Sustainability, v. II, n. 21, p. 5913, 2019. 